\title{
Robust Control Facing a Large Scale Parameter Variation in a Sensorless Vector Controlled Induction Motor Drive
}

YASSINE ZAHRAOUI

Mohamed V University

\author{
MOHAMED AKHERRAZ
}

Mohamed V University

\author{
CHAYMAE FAHASSA
}

Mohamed V University

Mohammadia School of Engineering Mohammadia School of Engineering Mohammadia School of Engineering Department of Electrical Engineering Department of Electrical Engineering Department of Electrical Engineering Street Ibn Sina, BP 765 Agdal-Rabat Street Ibn Sina, BP 765 Agdal-Rabat Street Ibn Sina, BP 765 Agdal-Rabat MOROCCO zahraoui.yassin@gmail.com

\section{MOROCCO}

akherraz@emi.ac.ma
MOROCCO

fahassa.chaymae@gmail.com

Abstract: In vector control systems using the slip frequency control method, the rotor resistance of induction motors is used to calculate a slip frequency. Thus the change in temperature and saturation levels cause the variation of rotor resistance value and hence the deterioration of the whole torque control characteristic. This paper presents a simulation of induction motor behavior facing a sudden parameter variation in very low speed basing on fuzzy logic perturbation rejection controllers, the rotor flux and speed are observed by an adaptive Luenberger observer based fuzzy adaptation mechanism. Simulation results show that the proposed control with the proposed fuzzy regulation provide good performance dynamic characteristics for a large scale parameter variation. All simulations have been realized in MatLab/Simulink.

Key-Words: Parameter variation, Rotor resistance variation, Induction motor drive, Direct vector control, Fuzzy logic regulation, Fuzzy adaptation mechanism, Speed sensorless, Adaptive Luenberger observer

Received: December 21, 2019. Revised: March 3, 2020. Accepted: March 15, 2020. Published: March 27, 2020.

\section{Introduction}

Induction motors (IM) are the most commonly and widely used electrical machines in several industrial applications, they are cheaper, rugged and easier to maintain comparing to other alternatives. But, their control is complex because of their nonlinear structure; accordingly, the main objective of the IM vector control methods is to provide an efficient performance in a simple structure. Vector control schemes are used in inverter-fed IM drives to obtain high performance [1] [2]. Crucial to the success of the vector control scheme is the knowledge of the instantaneous position of the rotor flux [3] [4].

The vector controlled IM drive is a very accepted method for high performance system response [1]. This technique was first formulated by Haase, in 1968, and Blaschke, in 1970. The direct version of the vector control requires a good knowledge of the module and the phase of the flux, measured quantities such as voltages and stator currents can be used to estimate or observe the rotor flux. However, the estimation accuracy is affected by the variation of machine parameters. Particularly, the rotor resistance variation becomes dominant by temperature and skin effect [5]. Compensation of this parameter is difficult because of inaccessibility [3].
The parameters in the machine model vary with temperature especially in low speed or because of magnetic saturation, therefore both the steady state and the dynamic operation of the system drive are then influenced [6] [7] [8] [9] [10]. Thus, the performance degradation is in the form of input-output torque nonlinearity and saturation of the machine, and several methods have come to the forefront to minimize the consequences of parameter sensitivity [11].

The design of a conventional control system is normally based on the mathematical model of a plant. if an accurate mathematical model is available with known parameters, it can be analyzed and a controller can be designed for the specified performance. Even if a plant model is well-known, there may be parameter variation problems. The $\mathrm{d}-\mathrm{q}$ dynamic model of IM is multivariable, complex and nonlinear, and may be a wide parameter variation problem in the system. To combat such problems, fuzzy logic control (FLC) replaces conventional control and it gives robust performance. Fuzzy theory has been introduced by Lotfi Zadeh [12] and it is one of the most used intelligent techniques. 
Over the last few years, the sensorless speed control of IM has received a great interest. Therefore, it is necessary to eliminate the speed sensor in order to reduce hardware and increase mechanical robustness. The main techniques of sensorless control of IM are: model reference adaptive systems (MRAS), extended Kalman filter (EKF) and adaptive Luenberger flux observer (ALO). Speed sensorless control methods of IM drive using the observed speed instead of the measured one have been studied in detail [2]. In this paper, the speed is observed from the instantaneous values of stator currents and voltages using the IM dynamic model in field rotating reference frame.

\section{IM Drive Modeling}

The mathematical model of a three-phase squirrel cage IM in d-q reference frame is given as [5]:

$$
\left\{\begin{array}{l}
\dot{x}=\mathbf{A} \cdot x+\mathbf{B} \cdot u \\
y=\mathbf{C} \cdot x
\end{array}\right.
$$

Where $x, u$ and $y$ are the state vector, the input vector and the output vector respectively.

$x=\left[\begin{array}{llll}i_{d s} & i_{q s} & \phi_{d r} & \phi_{q r}\end{array}\right]^{t} ; u=\left[\begin{array}{ll}u_{d s} & u_{q s}\end{array}\right]^{t} ; y=\left[\begin{array}{ll}i_{d s} & i_{q s}\end{array}\right]^{t}$

$$
\begin{aligned}
\mathbf{A} & =\left[\begin{array}{cccc}
-\lambda & \omega_{s} & \frac{K}{T_{r}} & K \omega_{r} \\
\omega_{s} & -\lambda & -K \omega_{r} & \frac{K}{T_{r}} \\
\frac{L_{m}}{T_{r}} & 0 & -\frac{1}{T_{r}} & \omega_{s l} \\
0 & \frac{L_{m}}{T_{r}} & -\omega_{s l} & -\frac{1}{T_{r}}
\end{array}\right] \\
& \mathbf{B}=\left[\begin{array}{cc}
\frac{1}{\sigma L_{s}} & 0 \\
0 & \frac{1}{\sigma L_{s}} \\
0 & 0 \\
0 & 0
\end{array}\right] \mathbf{C}=\left[\begin{array}{cccc}
1 & 0 & 0 & 0 \\
0 & 1 & 0 & 0
\end{array}\right] \\
\lambda & =\frac{R_{s}}{\sigma \cdot L_{s}}+\frac{1-\sigma}{\sigma \cdot T_{r}} ; K=\frac{1-\sigma}{\sigma \cdot L_{m}} ; \sigma=1-\frac{L_{m}^{2}}{L_{s} \cdot L_{r}} ; T_{r}=\frac{L_{r}}{R_{r}}
\end{aligned}
$$

Figure 1 demonstrates the state space mathematical model of the IM drive and Table 1 lists its rated power and parameters.

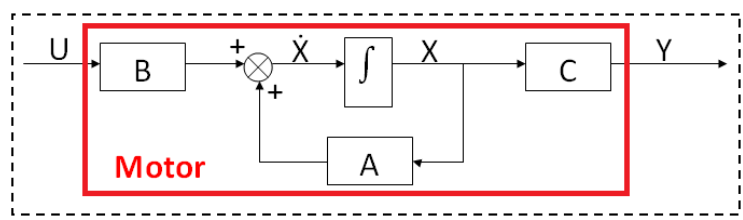

Figure 1: State space mathematical model of the IM drive

\section{Direct Vector Control}

In this type of control, the principal vector control parameters, $i_{d s}$ and $i_{q s}$, which are dc values in syn-
Table 1: IM rated power and parameters

\begin{tabular}{|c|c|}
\hline Rated power & $3 \mathrm{~kW}$ \\
\hline Voltage & $380 \mathrm{~V} \mathrm{STAR}$ \\
\hline Frequency & $50 \mathrm{~Hz}$ \\
\hline Pair pole & 2 \\
\hline Rated speed & $1440 \mathrm{rpm}$ \\
\hline Stator resistance & $2.2 \Omega$ \\
\hline Rotor resistance & $2.68 \Omega$ \\
\hline Stator inductance & $0.229 \mathrm{H}$ \\
\hline Rotor inductance & $0.229 \mathrm{H}$ \\
\hline Mutual inductance & $0.217 \mathrm{H}$ \\
\hline Moment of inertia & $0.047 \mathrm{~kg} . \mathrm{m}^{2}$ \\
\hline Viscous friction coefficient & $0.004 \mathrm{~N} . \mathrm{s} / \mathrm{rad}$ \\
\hline
\end{tabular}

chronously rotating frame, are converted to stationary frame with the help of unit vector $\theta_{s}$ generated from flux vector signals $\phi_{r \alpha}$ and $\phi_{r \beta}$. The resulting stationary frame signals are then converted to phase current commands for the inverter [5].

The norm of the rotor flux $\phi_{r}$ and its position $\theta_{s}$ used for the transformation of the coordinates are determined as follows:

$$
\begin{aligned}
& \phi_{r}=\sqrt{\phi_{r \alpha}^{2}+\phi_{r \beta}^{2}} \\
& \theta_{s}=\arctan \left(\frac{\phi_{r \beta}}{\phi_{r \alpha}}\right)
\end{aligned}
$$

Where $\phi_{r \alpha}$ and $\phi_{r \beta}$ are the rotor flux components in $\alpha-\beta$ reference frame.

In the proposed control scheme shown in Figure 2, $\phi_{r}$ and $\theta_{s}$ are not estimated but are instead observed by the adaptive Luenberger observer (ALO).

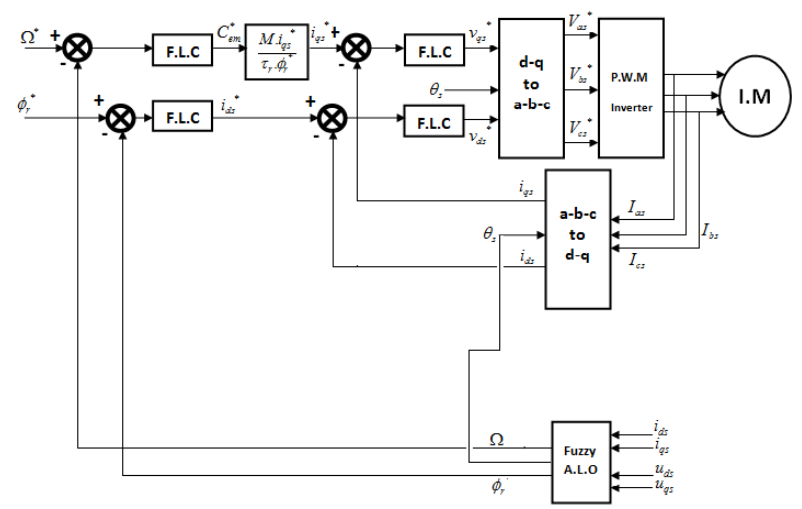

Figure 2: Block diagram of the proposed control 


\section{Fuzzy logic regulation}

The introduction of robust techniques such as fuzzy logic into process control has attracted an increasing interest in recent decades. Fuzzy control is applied when there is no precise mathematical model of the process to be controlled or when the latter has strong nonlinearities or inaccuracies [12] [13].

Generally, the design of a fuzzy controller for the regulation of electrical drives requires the choice of the following parameters: linguistic variables, membership functions, inference method and defuzzification strategy.

Figure 3 shows the design of a fuzzy regulator.

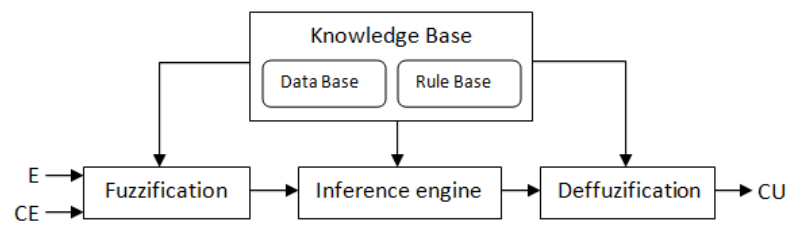

Figure 3: Fuzzy regulator design

\subsection{Speed loop regulation}

The structure of the speed fuzzy regulator is shown in Figure 4.

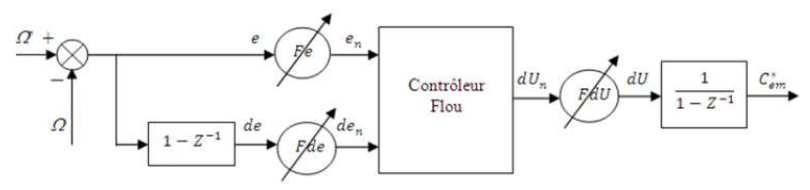

Figure 4: Speed fuzzy regulator structure

It generates an incremental output from the error signals and the variation of the error, where the error is expressed by:

$$
e_{k}=\Omega_{k}^{*}-\Omega_{k}
$$

The variation of the error can be approximated by:

$$
d e_{k}=\frac{e_{k}-e_{k-1}}{T_{s}}
$$

With $T_{s}$ is the sampling period, and the output of the regulator is given by:

$$
C_{e m_{k}}^{*}=C_{e m_{k-1}}^{*}+d U_{k}
$$

The input-output variables of the fuzzy controller can be normalized using gains called scaling factors. $e_{\Omega_{n}}=K_{e_{\Omega}} e_{\Omega} ; d e_{\Omega_{n}}=K_{d e_{\Omega}} d e_{\Omega} ; d U_{n}=K_{u_{\Omega}} d U$. $K_{e}, K_{d e}$ and $K_{C_{e m}^{*}}$ are scaling gains and are adjusted by trial and error. The proper choice of them allows to guarantee the stability and to improve the dynamic and static performances targeted of the system to be regulated [8].

Symmetrical triangular membership functions with 7 fuzzy sets are used for the input, output variables and the universe of discourse of all variables, covering the whole region, is expressed in per unit values. Linguistic variables are defined as: NB (Negative Big), NM (Negative Medium), NS (Negative Small), Z (Zero), PS (Positive Small), PM (Positive Medium) and PB (Positive Big), see Figures 5, 6 and 7 [14].

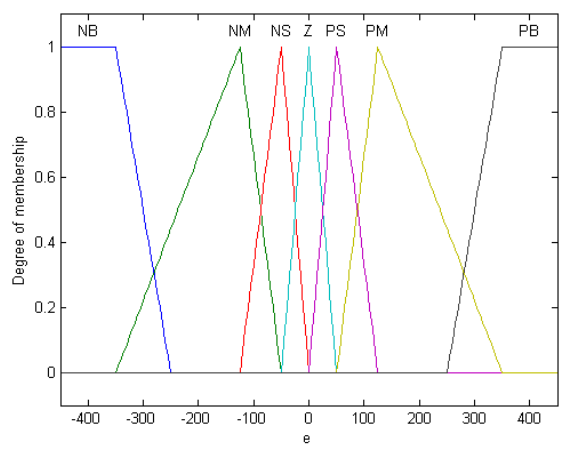

Figure 5: Membership function for input $\mathrm{E}$

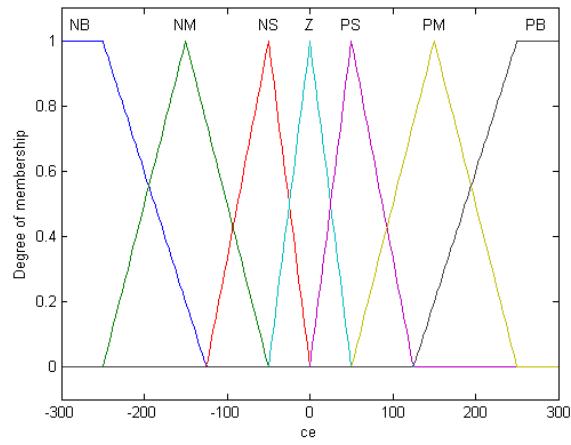

Figure 6: Membership function for input CE

The fuzzy rules, making it possible to determine the output variable of the regulator according to the input variables, are deduced from a table called inference table. In this case, it includes $7 \times 7=49$ rules as shown in Table 2.

$$
d U_{n}=\frac{\int x \mu_{R}(x) d x}{\int \mu_{R}(x) d x}
$$

The same structure was chosen also for the other controllers even that one of the adaptation mechanism. Except scaling gains, each controller has its own ones. 


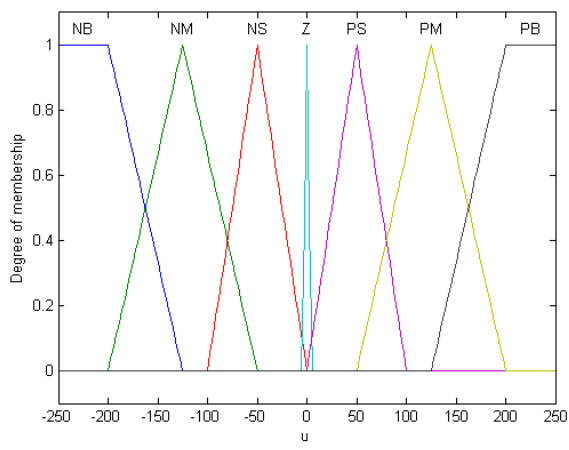

Figure 7: Membership function for output $\mathrm{U}$

Table 2: Fuzzy rule base

\begin{tabular}{|c||c|c|c|c|c|c|c|}
\hline ce/e & NB & NM & NS & ZE & PS & PM & PB \\
\hline \hline NB & NB & NB & NB & NB & NM & NS & ZE \\
\hline NM & NB & NB & NB & NM & NS & ZE & PS \\
\hline NS & NB & NB & NM & NS & ZE & PS & PM \\
\hline ZE & NB & NM & NS & ZE & PS & PM & PB \\
\hline PS & NM & NS & ZE & PS & PM & PB & PB \\
\hline PM & NS & ZE & PS & PM & PB & PB & PB \\
\hline PB & ZE & PS & PM & PB & PB & PB & PB \\
\hline
\end{tabular}

\section{Adaptive Luenberger observer for rotor flux and speed estimation}

The Adaptive flux observer is a deterministic type of observers based on a deterministic model of the system [2]. In this work, the adaptive Luenberger state observer is used to estimate the flux components and rotor speed of IM by including an adaptive mechanism based on the Lyapunov theory. In general, the equations of the ALO can be expressed as follow:

$$
\left\{\begin{array}{l}
\hat{\dot{x}}=\mathbf{A} \cdot \hat{x}+\mathbf{B} \cdot u+\mathbf{L} \cdot(y-\hat{y}) \\
\hat{y}=\mathbf{C} \cdot \hat{x}
\end{array}\right.
$$

The symbol ^ denotes estimated value and $\mathbf{L}$ is the observer gain matrix. The mechanism of adaptation speed is deduced by Lyapunov theory. The estimation error of the stator current and rotor flux, which is the difference between the observer and the model of the motor, is given by [2]:

$$
\dot{e}=(\mathbf{A}-\mathbf{L} . \mathbf{C}) \cdot e+\Delta \mathbf{A} . \hat{x}
$$

Where

$$
e=x-\hat{x}
$$

$$
\begin{gathered}
\Delta \mathbf{A}=\mathbf{A}-\tilde{\mathbf{A}}=\left[\begin{array}{cccc}
0 & 0 & 0 & K . \Delta \omega_{r} \\
0 & 0 & -K . \Delta \omega_{r} & 0 \\
0 & 0 & 0 & -\Delta \omega_{r} \\
0 & 0 & \Delta \omega_{r} & 0
\end{array}\right] \\
\Delta \omega_{r}=\omega_{r}-\hat{\omega}_{r}
\end{gathered}
$$

We consider the following Lyapunov function:

$$
V=e^{t} \cdot e+\frac{\left(\Delta \omega_{r}\right)^{2}}{\lambda}
$$

where $\lambda$ is a positive coefficient, its derivative is given as follow:

$$
\begin{aligned}
& \dot{V}=e^{t}\left[(\mathbf{A}-\mathbf{L} \mathbf{C})^{t}+(\mathbf{A}-\mathbf{L} \mathbf{C})\right] e-2 K \Delta \omega_{r}\left(e_{i_{s \alpha}} \hat{\phi_{r \beta}}-e_{i_{s \beta}} \hat{\phi_{r \alpha}}\right) \\
& +\frac{2}{\lambda} \Delta \omega_{r} \dot{\hat{\omega}_{r}}
\end{aligned}
$$

With $\hat{\omega}_{r}$ is the estimated rotor speed. The adaptation law for the estimation of the rotor speed can be deduced by the equality between the second and third terms of Equation (16):

$$
\hat{\omega_{r}}=\int \lambda \cdot K \cdot\left(e_{i_{s \alpha}} \cdot \hat{\phi_{r \beta}}-e_{i_{s \beta}} \cdot \hat{\phi_{r \alpha}}\right) \cdot d t
$$

The feedback gain matrix $\mathbf{L}$ is chosen to ensure the fast and robust dynamic performance of the closed loop observer [2].

$$
\mathbf{L}=\left[\begin{array}{cc}
l_{1} & -l_{2} \\
l_{2} & l_{1} \\
l_{3} & -l_{4} \\
l_{4} & l_{3}
\end{array}\right]
$$

with $l_{1}, l_{2}, l_{3}$ and $l_{4}$ are given by: $l_{1}=\left(k_{1}-1\right) \cdot\left(\gamma+\frac{1}{T_{r}}\right) ; l_{2}=-\left(k_{1}-1\right) \cdot \hat{\omega}_{r}$ $l_{3}=\frac{\left(k_{1}^{2}-1\right)}{K} \cdot\left(\gamma-K \cdot \frac{L_{m}}{T_{r}}\right)+\frac{\left(k_{1}-1\right)}{K} \cdot\left(\gamma+\frac{1}{T_{r}}\right)$ $l_{4}=-\frac{\left(k_{1}-1\right)}{K} \cdot \hat{\omega}_{r}$

where $k_{1}$ is a positive coefficient obtained by pole placement approach [2], a wise choice was made for its value which is 1.06. Fuzzy logic control (FLC) in adaptation mechanism replaces conventional control and it gives robust performance against parameter variation and machine saturation.

The state space mathematical model of the observer is illustrated by Figure 8.

\section{Simulation Results}

The reference speed chosen for all tests is a step of 5 $\mathrm{rad} / \mathrm{s}$, because it is the hardest for most control processes.

A load of 10 N.m is applied at $0.4 \mathrm{~s}$ and removed at $0.8 \mathrm{~s}$ in order to show the system stability. 


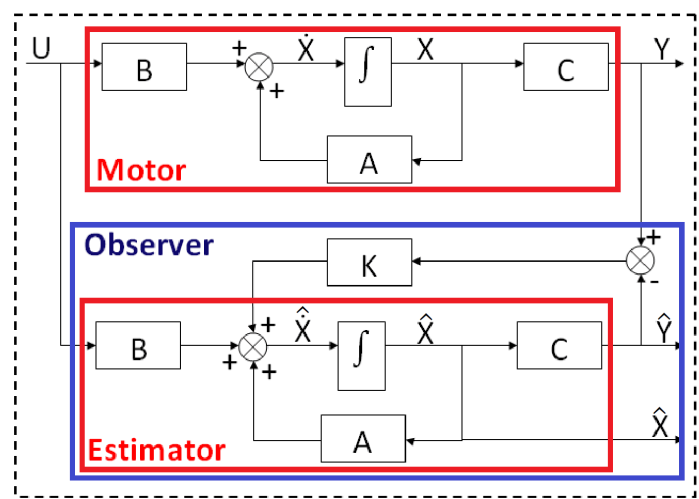

Figure 8: State space mathematical model of the observer

\subsection{Operating up to $300 \%$ of rotor resistance variation at very low speed $5 \mathrm{rad} / \mathrm{s}$}

The rotor resistance is the main parameter of the vector control scheme because it is used to calculate the slip frequency. In Figure 9, the rotor resistance is suddenly varied 3 times of its rated value from $2.68 \Omega$ to $8.04 \Omega$ at 1 s.

In classical PI vector controlled IM drive, the control will normally be lost especially at very low speed and the system will not be able to track the reference perfectly. But with FLC controllers, the rotor speed fluctuate a little and did not deviate from the reference after varying the rotor resistance value.

\subsection{Operating up to $150 \%$ of stator resis- tance variation at very low speed $5 \mathrm{rad} / \mathrm{s}$}

Stator resistance is a delicate parameter, a tiny variation of its value leads to a deterioration of the whole system characteristic. In Figure 10, the stator resistance is suddenly varied one and half times of its rated value from $2.2 \Omega$ to $3.3 \Omega$ at $1 \mathrm{~s}$. The rotor speed did not fluctuate but deviate a little from the reference and is still tracking it well.

Speed error demonstrates the good performance of fuzzy ALO against instant load perturbation and parameter variation.

\section{Conclusion}

This paper proposed a method to compensate the rotor and stator resistance sudden variation basing on fuzzy logic perturbation rejection capabilities. The obtained results have confirmed the efficiency and the precision of this control during the sudden parameter variation and load torque disturbance. The overall system was tested under a large rotor resistance inter- val up to $300 \%$ of its rated value, and up to $150 \%$ of stator resistance variation. Simulation results showed also the good performance of the speed observation at very low speed because the fuzzy logic controller in adaptation mechanism gives better robustness against the instant load torque disturbance.

[Nomenclature]

\begin{tabular}{|c|c|}
\hline$i_{d s}, i_{q s}$ & d-q stator current components \\
\hline$\phi_{r \alpha}, \phi_{r \beta}$ & $\alpha$ - $\beta$ rotor flux components \\
\hline$\phi_{d r}, \phi_{q r}$ & d-q rotor flux components \\
\hline$u_{d s}, u_{q s}$ & d-q stator voltage components \\
\hline$T_{r}$ & Rotor time constant \\
\hline$\Omega$ & Rotor mechanical speed \\
\hline$\omega_{r}$ & Rotor electrical speed \\
\hline$\omega_{s}$ & Stator frequency \\
\hline$\omega_{s l}$ & Slip frequency \\
\hline $\mathrm{p}$ & Number of pole pairs \\
\hline$C_{e m}$ & Electromagnetic torque \\
\hline$R_{s}, R_{r}$ & Stator, rotor resistance \\
\hline$L_{s}, L_{r}, L_{m}$ & Stator, rotor, mutual inductance \\
\hline$\sigma$ & Leakage coefficient \\
\hline
\end{tabular}




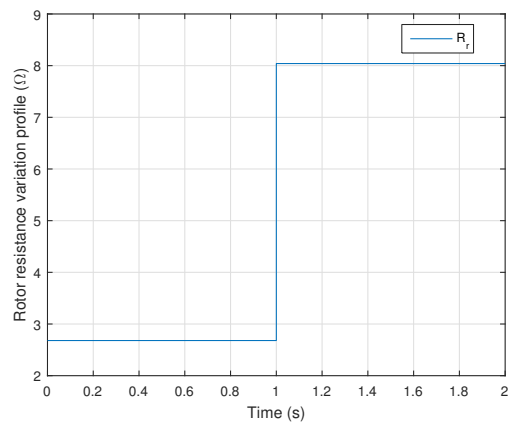

(a) Rotor resistance variation profile

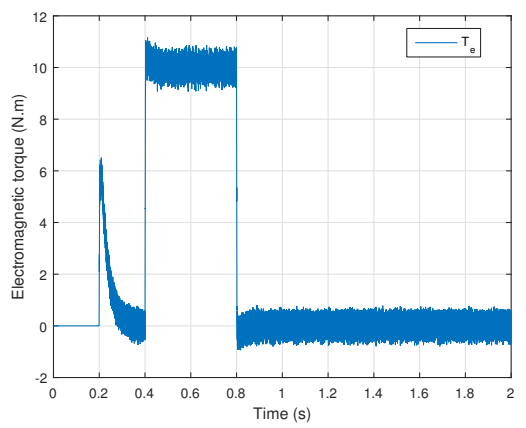

(d) Torque

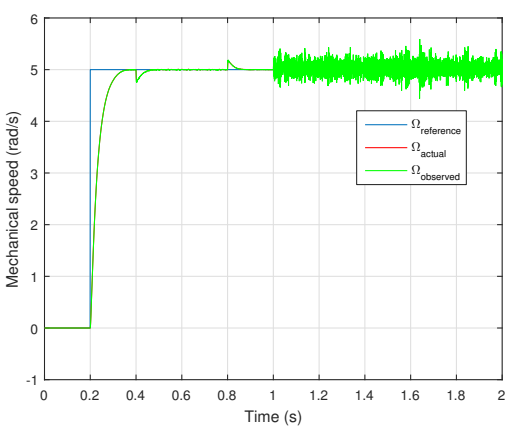

(b) Speed

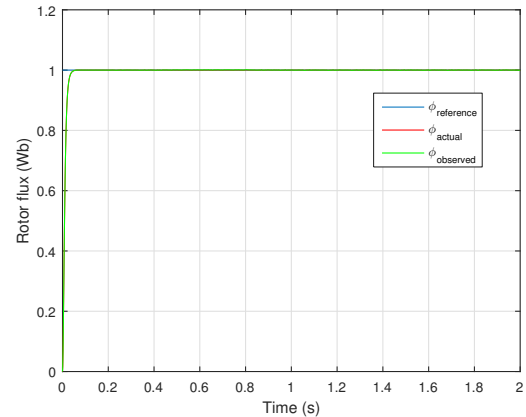

(e) Rotor flux

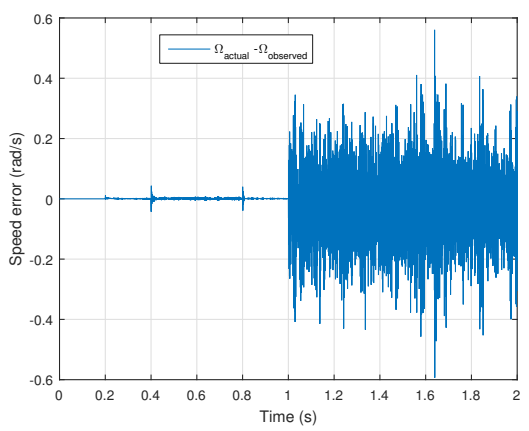

(c) Speed error

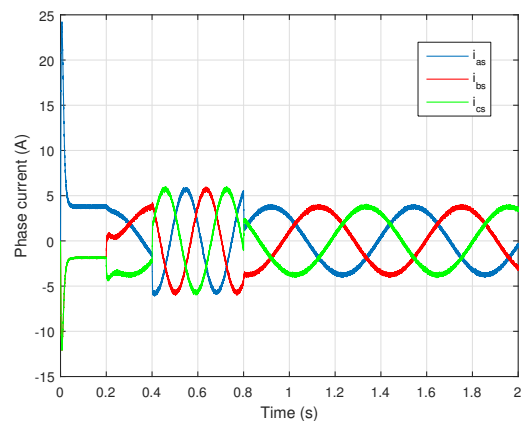

(f) Stator phase current

Figure 9: Operating up to $300 \%$ of rotor resistance variation at $5 \mathrm{rad} / \mathrm{s}$

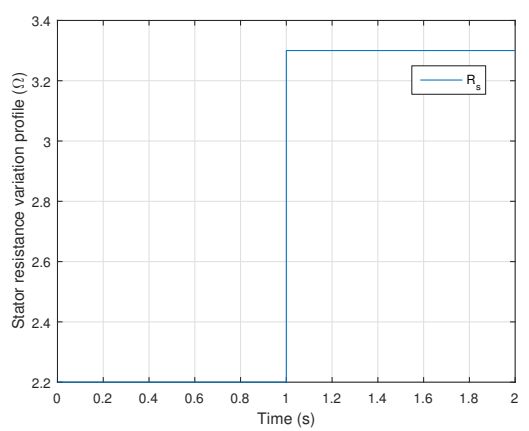

(a) Stator resistance variation profile

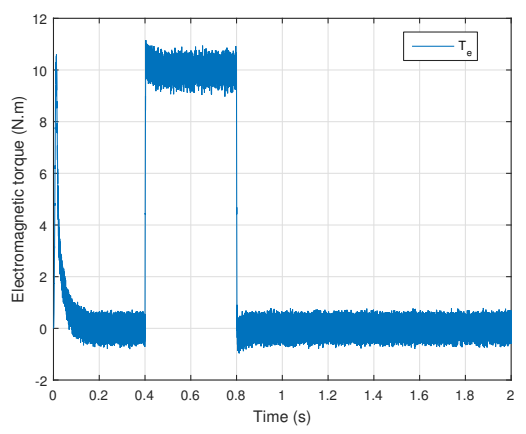

(d) Torque

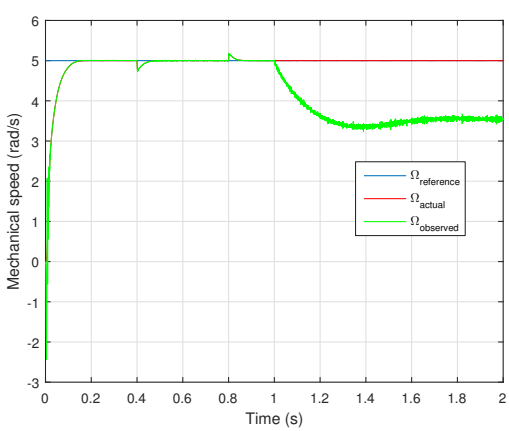

(b) Speed

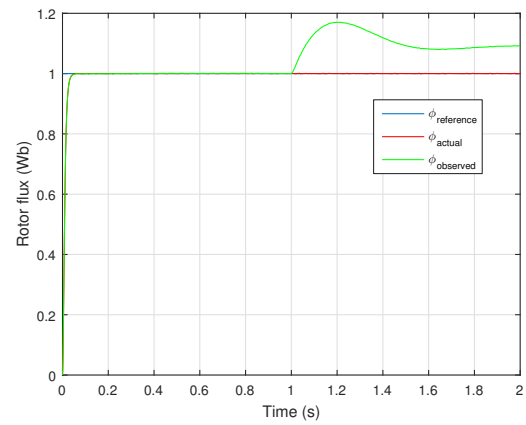

(e) Rotor flux

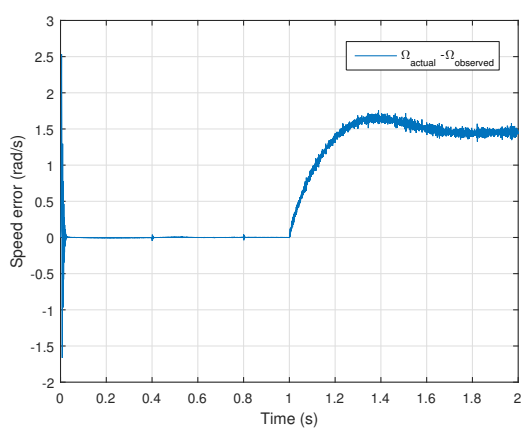

(c) Speed error

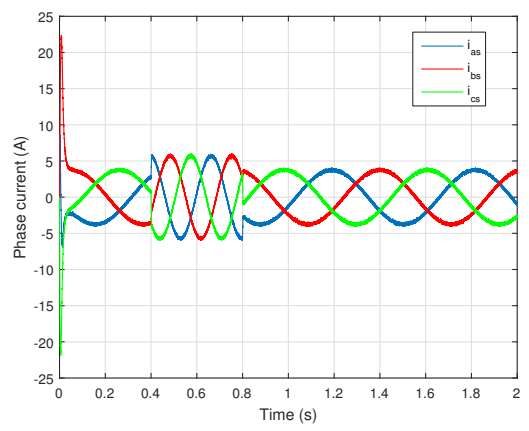

(f) Stator phase current

Figure 10: Operating up to $150 \%$ of stator resistance variation at $5 \mathrm{rad} / \mathrm{s}$ 


\section{References:}

[1] J.-P. Caron and J.-P. Hautier, Modelisation et commande de la machine asynchrome. Paris: Editions Technip, 1995.

[2] P. Vas, Sensorless Vector and Direct Torque Control. Oxford University Press, 1998.

[3] R. Krishnan, Electric Motor Drives: Modeling, Analysis, and Control, 1st ed. Upper Saddle River, N.J: Pearson, Feb. 2001.

[4] J. D. Irwin, Control in Power Electronics: Selected Problems, 1st ed., M. P. Kazmierkowski, R. Krishnan, and F. Blaabjerg, Eds. Amsterdam ; New York: Academic Press, Sep. 2002.

[5] B. K. Bose, Modern Power Electronics and AC Drives, 1st ed. Upper Saddle River, NJ: Prentice Hall, Oct. 2001.

[6] T. Yamada, Y. Yamamoto, T. Ichioka, and T. Niwa, "Compensation for Parameters Variation of Induction Motor Improved Torque Control Characteristics at Low and High Speed Region," IEEJ Transactions on Industry Applications, vol. 112, no. 2, pp. 107-116, 1992.

[7] G. Rafajlovski, E. Ratz, D. Manov, and D. Hristovski, "Assessment of motor parameter variation in vector controlled induction motor," in , Proceedings of the IEEE International Symposium on Industrial Electronics, 1997. ISIE '97, vol. 2, Jul. 1997, pp. 522-526 vol.2.

[8] S. Anil Chandrakanth, T. Chelliah, and S. Srivastava, "Efficiency determination of induction motor and its sensitivity analysis towards parameter variation," Int. J. of Artificial Intelligence and Soft Computing, vol. 4, pp. 144-163, Jan. 2014.

[9] E. E. D. M. G. C. S. Cauet, L. Rambault, "Linearizing Control of an Induction Motor Subjected to Parameter Variation," Electric Power Components and Systems, vol. 29, no. 7, pp. 629-644, Jul. 2001.

[10] M. J. M. Wang, E. Levi, "Compensation of Parameter Variation Effects in Sensorless Indirect Vector Controlled Induction Machines Using Model-Based Approach," Electric Machines \& Power Systems, vol. 27, no. 9, pp. 1001-1027, Aug. 1999.

[11] R. Krishnan and F. C. Doran, "Study of Parameter Sensitivity in High-Performance Inverter-Fed
Induction Motor Drive Systems," IEEE Transactions on Industry Applications, vol. IA-23, no. 4, pp. 623-635, Jul. 1987.

[12] L. A. Zadeh, "Fuzzy sets," Information and Control, vol. 8, no. 3, pp. 338-353, Jun. 1965.

[13] C. Martin, M. Bermudez, F. Barrero, M. R. Arahal, X. Kestelyn, and M. J. Duran, "Sensitivity of predictive controllers to parameter variation in five-phase induction motor drives," Control Engineering Practice, vol. 68, no. Supplement C, pp. 23-31, Nov. 2017.

[14] Y. Zahraoui, A. Bennassar, M. Akherraz, and A. Essalmi, "Indirect vector control of induction motor using an extended Kalman observer and fuzzy logic controllers," in 2015 3rd International Renewable and Sustainable Energy Conference (IRSEC), Dec. 2015, pp. 1-6. 